\title{
BMJ Open Characteristics of NPS use in patients admitted to acute psychiatric services in Southeast Scotland: a retrospective cross-sectional analysis following public health interventions
}

\author{
Kyle H Bennett, ${ }^{1}$ Helen M Hare ${ }^{2}$ Robert M Waller, ${ }^{3}$ Helen L Alderson, ${ }^{4}$ \\ Stephen Lawrie ${ }^{5}$
}

To cite: Bennett KH, Hare HM, Waller RM, et al. Characteristics of NPS use in patients admitted to acute psychiatric services in Southeast Scotland: a retrospective cross-sectional analysis following public health interventions. BMJ Open 2017;7:e015716. doi:10.1136/ bmjopen-2016-015716

- Prepublication history and additional material for this paper are available online. To view these files, please visit the journal online (http://dx.doi org/10.1136/bmjopen-2016015716).

Received 22 December 2016 Revised 20 June 2017 Accepted 21 September 2017

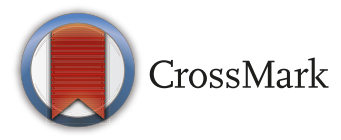

${ }^{1}$ School of Medicine, University of Edinburgh College of Medicine and Veterinary Medicine, Edinburgh, UK ${ }^{2}$ Department of Psychiatry, Royal Edinburgh Hospital, Edinburgh, UK

${ }^{3} \mathrm{He}$ Puna Waiora Adult Mental Health Inpatient Unit, Waitemata District Health Board, Auckland, New Zealand

${ }^{4}$ Department of Psychiatry, Queen Margaret Hospital, Dunfermline, Fife, UK

${ }^{5}$ Department of Psychiatry, University of Edinburgh, Edinburgh, UK

Correspondence to Dr Helen L Alderson; h.alderson@nhs.net

\section{ABSTRACT}

Objectives Assess the impact of selective prohibition and seizure of novel psychoactive substances (NPS) supply on NPS use prevalence within psychiatric admissions and evaluate demographic characteristics of current NPS users.

Design A 6-month retrospective cross-sectional analysis of discharge letters between 1 0ctober 2015 and 31 March 2016.

Setting General psychiatry inpatients and intensive home treatment team (IHTT) community patients at a psychiatric hospital in a Scottish city.

Participants All participants were between the ages of 18 and 65 years. After application of exclusion criteria, 473 discharge letters of general psychiatry patients were deemed suitable for analysis and $264 \mathrm{IHTT}$ patient discharge letters were analysed.

Interventions A nationwide temporary class drug order (TCDO) was placed on 10 April 2015 reclassifying methylphenidate-related compounds as class $B$ substances. On 15 0ctober 2015, local forfeiture orders were granted to trading standards permitting the seizure of NPS supplies.

Primary and secondary outcome measures The primary outcome measure was to determine the prevalence of NPS use in two cohorts. Second, demographic features of patients and details regarding their psychiatric presentation were analysed.

Results The prevalence of NPS use in general psychiatry and IHTT patients was $6.6 \%$ and $3.4 \%$, respectively. Inpatients using NPS compared with non-users were more likely to be men (OR $2.92,95 \% \mathrm{Cl} 1.28$ to $6.66, \mathrm{P}=0.009)$, have a forensic history (OR 5.03, Cl 2.39 to 10.59 ,

$\mathrm{P}<0.001)$ and be detained under an Emergency Detention Certificate (OR 3.50, $\mathrm{Cl} 1.56$ to $7.82, \mathrm{P}=0.004)$. NPS users were also more likely to be diagnosed under International Statistical Classification of Diseases and Related Health Problems, Version 10, F10-19 (OR 9.97, Cl 4.62 to 21.49, $\mathrm{P}<0.001$ ).

Conclusions Compared with previous work, psychiatric inpatient NPS use has fallen. NPS continue to be used by a demographic previously described resulting in presentations consistent with a drug-induced psychosis and at times requiring detention under the Mental
Strengths and limitations of this study

- Recent public health interventions concerning novel psychoactive substances (NPS) have been evaluated, specifically their association with a reduction in the prevalence of NPS use in a psychiatric population.

- The strain placed on services by NPS use has been quantified by studying the duration of patients' admissions and the likelihood that they are detained under the Mental Health Act.

- As the NPS user sample was relatively small compared with previous work, figures pertaining to the demographic features of this group should be interpreted with caution.

- A number of the study outcomes were poorly recorded for in discharge letters, which may be accounted for by the variation in the quality of discharge letters.

- The study period encompasses a 6-month period following the issue of forfeiture orders on 15 October 2015; therefore, it is not possible to comment if the reduction of NPS use within this population is more attributable to a particular one of the two interventions.

Health Act. Further research is required to evaluate the effectiveness of the recent prohibition of all NPS.

\section{INTRODUCTION}

\section{Background}

In recent years, a new public health issue has arisen: novel psychoactive substances (NPS), more commonly known as 'legal highs'. The European Monitoring Centre for Drugs and Drug Addiction (EMCDDA) defines an NPS as a drug not controlled by UN drug conventions with potential to cause as much public health risk as classic illicit drugs. ${ }^{1}$ Attempts have been made to classify NPS chemically, ${ }^{2}$ of which synthetic cannabinoids (cannabis 


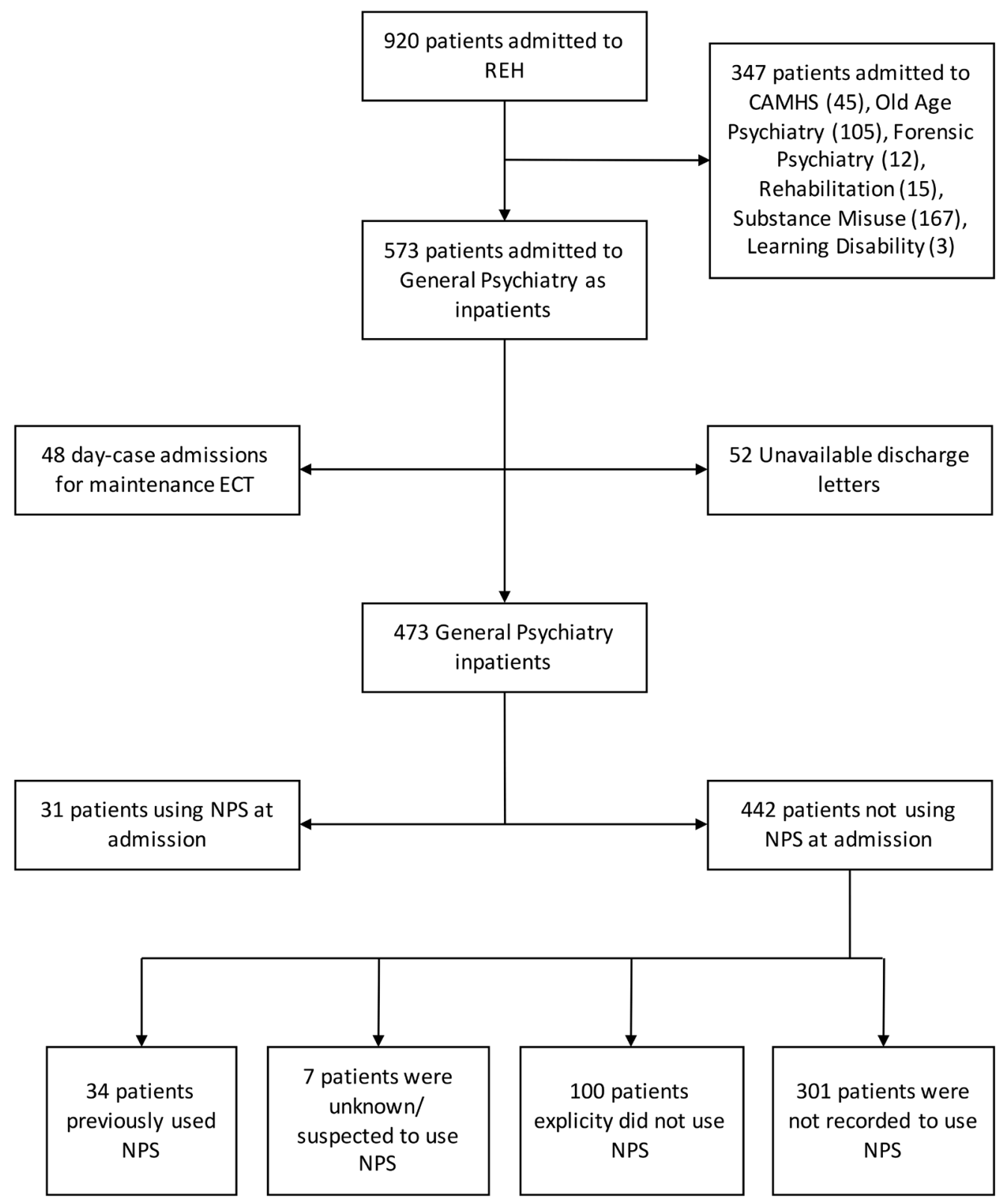

Figure 1 Flow chart of inclusion/exclusion criteria and patient groups. Subgroups of the lowest tier in the flow chart were analysed collectively as non-NPS users. CAMHS, Child and Adolescent Mental Health Services; ECT, electroconvulsive therapy; NPS, novel psychoactive substance; REH, Royal Edinburgh Hospital.

replacements) and synthetic cathinones (stimulants) account for the majority. ${ }^{3}$ However, in 2014 alone over a hundred new NPS were introduced to the market, signifying the challenges in studying and classifying such substances. ${ }^{3}$

Over the past decade, NPS have been assimilated into the repertoire of drugs available to habitual drug users. ${ }^{4}$ Sophisticated marketing of NPS has rendered them as socially acceptable and safe, ${ }^{5}$ despite their involvement in numerous drug-related deaths. ${ }^{6}$ Until recently, NPS have escaped prohibitive legislation by including labels on packaging: 'not for human consumption' or 'for research only, ${ }^{7}$ despite the contrary insinuations made elsewhere.

In Edinburgh, during 2014, ${ }^{5}$ ethylphenidate, a methylphenidate derivative, resulted in a significant burden for Police Scotland; the incidence of legal-high related casualties increased amidst reports of "bizarre and violent behaviour'. ${ }^{8}$ As well as admissions to acute mental health services, a cluster of serious soft-tissue infections and necrotic ulcers resulted from parenteral ethylphenidate use. ${ }^{89}$ Ethylphenidate was first recognised in UK 'headshops' (drug paraphernalia shops) in November 2011 via the UK Forensics Early Warning System ${ }^{10}$ and was subsequently reported to the EMCDDA. ${ }^{7}$ However, its use had already been widely discussed on online user forums before this time. ${ }^{11}$ Its effects bear similarity to that of cocaine and, to some extent, amphetamines, including euphoria, increased sociability, ${ }^{12}$ tachycardia, hypertension, palpitations, ${ }^{13}$ multisensory hallucinations ${ }^{9}$ and a considerable urge to reuse. ${ }^{12}{ }^{14}$ NPS in general have been 


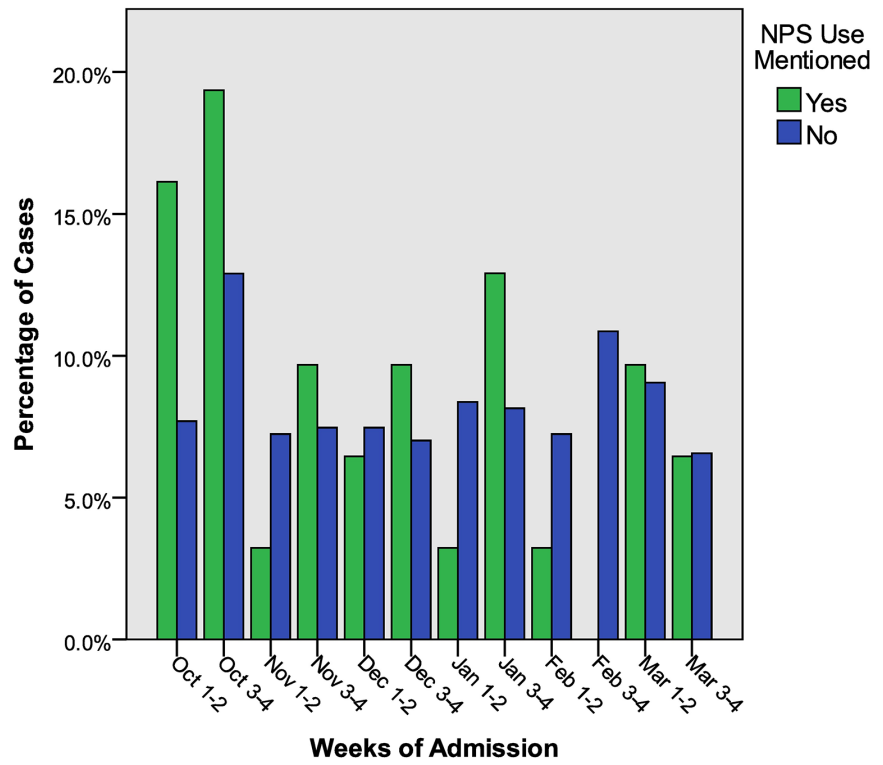

Figure 2 The percentage of novel psychoactive substance (NPS) users and non-NPS users admitted in fortnightly intervals between October 2015 and March 2016.

associated with various psychiatric symptoms, which often present as an acute transient psychotic episode ${ }^{15}$ although the long-term impact on mental health is unknown. Ethylphenidate has been implicated in numerous fatalities ${ }^{616}$ and was, in one study, discovered in the possession of two subjects following suicide, suggesting a possible association with psychiatric illness. ${ }^{17}$

On 10 April 2015, the UK government responded by placing a temporary class drug order (TCDO) under the Misuse of Drugs Act 1971 on methylphenidate derivatives making supply and production, but not possession, punishable by imprisonment. ${ }^{18} 19$ Police Scotland reported a reduction in parenteral infections, publicly discarded needles and emergency admissions since this time. ${ }^{20}$ Forfeiture orders were granted on 15 October 2015 from the Sheriff Court in Edinburgh to Trading Standards permitting seizure of all NPS from head-shops. ${ }^{21}$ More recently, the Psychoactive Substances Act (2016) was imposed, which criminalises any NPS-a so-called blanket ban. ${ }^{22}$ However, other substances classified under the Misuse of Drugs Act such as mephedrone have, since their selective banning, become integrated into the clubbing environment ${ }^{23}$ and distributed under the guise of legal NPS, ${ }^{24}$ raising questions as to how effective specific legislative bans are.

In recent years, the public health issue of NPS use has been widely researched, including a previous study at this centre. Work by Stanley et al established that $22.2 \%$ of inpatients admitted to acute psychiatric wards at the Royal Edinburgh Hospital were using NPS, 59.3\% of whom had psychiatric symptoms attributable to their drug use. ${ }^{25}$ Since legislative changes have been implemented, no research has been conducted to analyse ongoing trends in NPS use.

\section{Objectives}

This study aimed to examine the possible impact of the recent public health interventions on NPS-related psychiatric admissions, building on the findings of a previous study by Stanley et $a .^{25}$ In addition to examining admissions to the acute psychiatric inpatient wards at the Royal Edinburgh Hospital, patients admitted to the intensive home treatment team (IHTT), a community-based psychiatric crisis team, covering the same catchment area as the Royal Edinburgh Hospital, were also included. The study aimed to evaluate how effective recent public health interventions have been in reducing NPS use, as reflected in NPS-related admissions to these two services. The primary hypothesis was that the interventions made on a national and local level would have reduced the prevalence of NPS use in patients admitted to these services.

\section{METHODS}

\section{Study design and setting}

This study was a retrospective cross-sectional review of discharge letters written for two cohorts of psychiatric patients-general psychiatry inpatients and community-based IHTT patients-at the Royal Edinburgh Hospital in Edinburgh, UK. Discharge letters were written by medical staff for inpatients; IHTT discharge letters were written by community psychiatric nurses and reviewed by medical staff.

\section{Participants}

Adult patients (18-65 years old) admitted to the Royal Edinburgh Hospital between 1 October 2015 and 31 March 2016 were identified from the TrakCare Electronic Patient Record (InterSystems) database. ${ }^{26}$ Only patients admitted to general psychiatry who had been subsequently discharged from hospital by 30 June 2016 were included in the study. Those admitted to specialist services or admitted as inpatient day-cases for electroconvulsive therapy were excluded (figure 1). All adult patients admitted to IHTT over the same period were included.

\section{Data collection}

SAP BusinessObjects (SAP) ${ }^{27}$ was used by KHB and RMW to extract details regarding patient admissions, including Principal Diagnosis and Code (consistent with International Statistical Classification of Diseases and Related Health Problems, Version 10 (ICD-10) ), ${ }^{28}$ duration of admission and legal status (Mental Health (Care and Treatment) (Scotland) Act $2003^{29}$ while in hospital, which was categorised as informal, Emergency Detention Certificate (EDC), Short-Term Detention Certificate (STDC) or Compulsory Treatment Order (CTO). Patients were assigned subject numbers to ensure anonymity.

Additional study outcomes relating to patient demographics (age, gender, employment status and home circumstances), forensic history (any forensic history of note and custodial sentences), substance use (NPS use, contribution to psychiatric presentation, name of NPS, route of administration and other substance use) and 
any psychiatric symptoms recorded during admission were collected from patient discharge letters on e-Health systems by KHB. Such data were collected during clerking of patients and routine consultations; thus, reporting of these outcomes were dependent on clinical inquiry and patient self-reporting. Some discharge letters were extractable as free-text from TrakCare (Intersystems) using SAP BusinessObjects. Others were only available as PDF (Portable Document Format) files uploaded to the linked document storage system SCI-Store. ${ }^{30}$ Both locations were searched. All data were recorded in the data collection tool provided in the online supplementary file.

When recorded, NPS brand names were cross-checked on an online database of NPS to reveal the active ingredients reported to be present. ${ }^{31}$ These chemicals were then classified in accordance with the Drugs Wheel to provide an NPS type ${ }^{32}$; supporting evidence was found elsewhere if these chemicals were not reported in the Drug Wheel. ${ }^{33}$ Where study outcomes were not recorded in discharge letters, these were assumed to be negative and grouped with explicitly negative data. Patients referred to IHTT were identified using SAP and the above study outcomes were collected from IHTT discharge letters either within a free-text TrakCare extract or uploaded PDFs as above. Data collection was repeated for a sample of subjects by HMH for quality control purposes.

\section{Statistical methods}

Statistical analysis was carried out using SPSS V.22.0.0.1 (IBM). Independent two-sample Student's t-tests were used to assess the differences in continuous dependent variables between NPS users and non-NPS users. ORs were generated and Pearson $\chi^{2}$ tests were used to compare differences between these groups for remaining categorical variables; Fisher's exact test and Phi/Cramer's V symmetric measures were performed where appropriate. Two-tailed two-sample Z-tests were performed for comparisons between the proportion of NPS users in this study and those in Stanley et al a study conducted under the same methodology that reported the prevalence of NPS use in the general psychiatry population between July and December $2014 .^{25}$

\section{Ethics and database protection}

This study was assessed by the local clinical governance team who deemed that it did not require ethics committee approval. Data were collected into an Excel spreadsheet using a coded ID number which could not be used to retrospectively identify individual patients. This spreadsheet was password protected and stored on NHS servers only. The password was available only to the authors; each had access via their NHS user ID which allowed tracking of changes made.

\section{RESULTS}

A total of 473 general psychiatry inpatient cases were included in the analysis after application of the exclusion criteria (figure 1). Of these, 31 patients were reported to be currently using NPS on admission. A two-tailed two-sample Z-test between the proportion of NPS users in this population $(6.6 \%, \mathrm{n}=473)$ and of that in Stanley et al $(22.2 \%, \mathrm{n}=488)^{25}$ revealed a statistically significant difference $(\mathrm{z}=6.7, \mathrm{P}<0.001)$. A total of 264 patients were discharged from IHTT, of which nine cases $(3.4 \%)$ were identified as NPS users at the time of admission. Across both cohorts, the prevalence of NPS use was 5.4\%.

For general psychiatry and IHTT NPS users, the types of NPS were recorded in $38.7 \%$ and $11.1 \%$ of cases, respectively. NPS use was recorded to contribute to the psychiatric presentation $77.4 \%$ and $22.2 \%$ of the time. Of all NPS products identified in the general psychiatry cohort, including multiple NPS in individual patients, 24.2\% contained stimulants (ethylphenidate, methiopropamine (MPA) and 3-fluorophenmetrazine (3-FPM)) and 18.2\% were synthetic cannabinoids. Three of the recorded NPS products have been reported to include two active ingredients; 'Magic crystals' are reported to include 3-FPM and ethylphenidate whereas 'Pink panther' is reported to include MDAI, an empathogen, and MPA and 'K-Pax' is reported to include methoxphenidine, a dissociative, in addition to 3-FPM. ${ }^{31}$ The use of MPA could be identified in only one case of the IHTT cohort $(11.1 \%)$. Data from the IHTT cohort were excluded from further analysis due to insufficient recording of outcome measures in discharge letters.

Figure 2 shows the percentage of admissions for NPS users and non-NPS users over the study period (OctoberMarch). The month of October accounted for the largest proportion of NPS user admissions in which $16.1 \%$ were admitted in the first fortnight and $19.4 \%$ in the remainder of the month (a total $35.5 \%$ across October). However, compared with non-NPS users these figures were not statistically significant.

The collective length of admission for all NPS users amounted to $4.41 \%$ of the total length of admission for all inpatients. Mean length of admission between NPS users and non-NPS users was not statistically significant.

NPS users were significantly more likely to be detained under the Mental Health Act (MHA) than non-NPS users (OR 3.37, 95\% CI1.57 to 7.21, $\mathrm{P}=0.002$ ). When individual modes of detention were considered (EDC, STDC and CTO), there was a statistically significant difference between NPS users and non-NPS users only in detention under an EDC, where $32.3 \%$ of NPS users were detained under this order compared with $12.0 \%$ of non-NPS users (OR 3.50, CI 1.56 to 7.82, $\mathrm{P}=0.004$ ).

The demographic features of NPS users compared with non-NPS users are shown in table 1. Significant differences were observed between NPS users and non-NPS users for mean age $(35.1 \pm 9.8$ (SD) years vs $40.0 \pm 11.7$ $(\mathrm{SD})$ years, $\mathrm{P}=0.023)$. Furthermore, a bimodal distribution of age ranges emerged in NPS users where peaks were observed in the 18-25 and 41-45 age ranges. Age of NPS users was significantly more likely to be within the latter range compared with non-NPS users (OR 2.87, 
Table 1 Demographic features of NPS users and non-NPS users

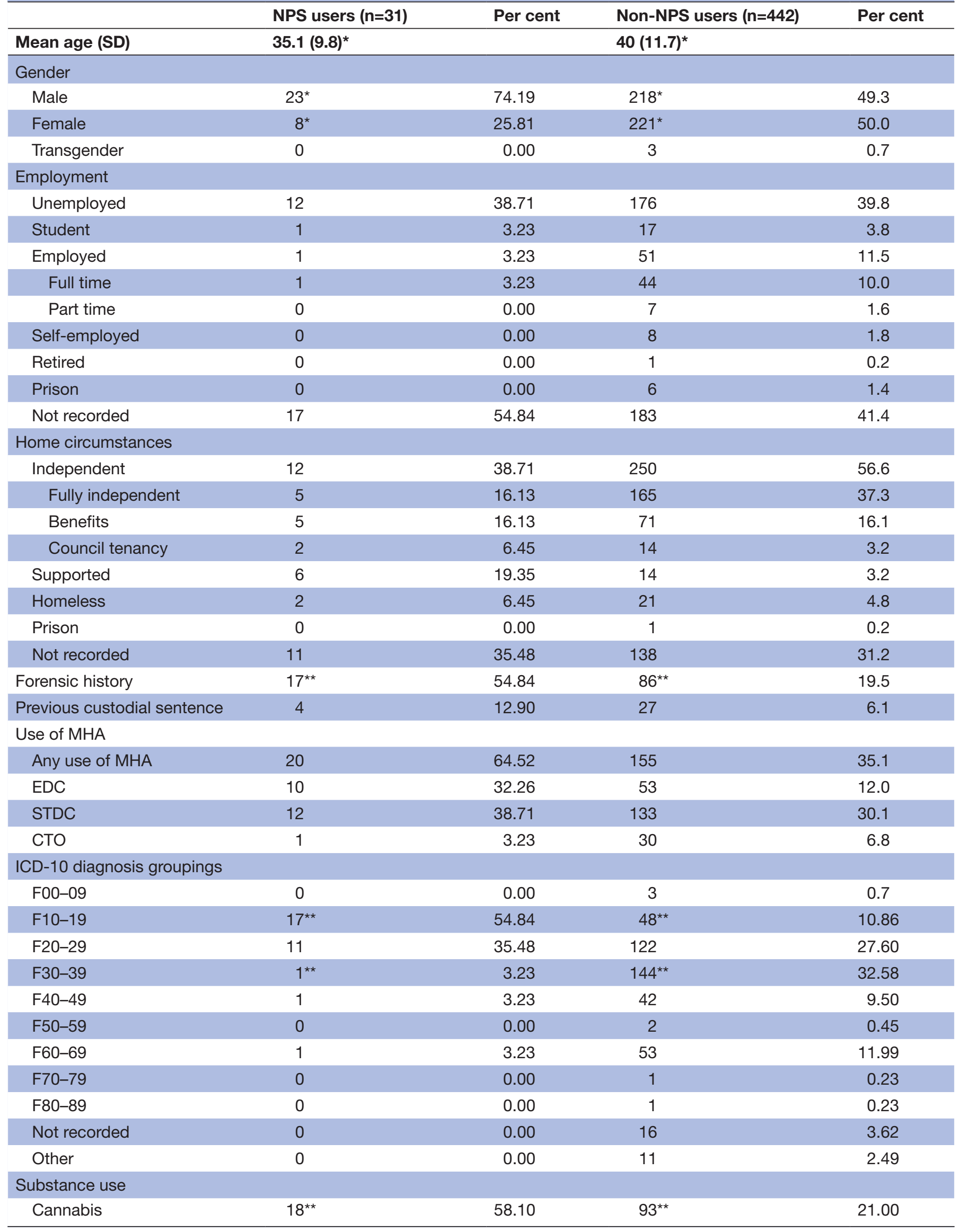


Table 1 Continued

\begin{tabular}{|c|c|c|c|c|}
\hline & NPS users $(n=31)$ & Per cent & Non-NPS users $(n=442)$ & Per cent \\
\hline Mean age (SD) & $35.1(9.8)^{*}$ & & $40(11.7)^{*}$ & \\
\hline Alcohol & 8 & 25.80 & 120 & 27.10 \\
\hline Substitute opiates & 7 & 22.60 & 46 & 10.40 \\
\hline Other & $7^{\star}$ & 22.60 & $17^{*}$ & 3.80 \\
\hline Amphetamines & 3 & 9.70 & 25 & 5.70 \\
\hline Cocaine & 3 & 9.70 & 39 & 8.80 \\
\hline Benzodiazepines & 3 & 9.70 & 34 & 7.70 \\
\hline Any substance use & $26^{\star \star}$ & 83.90 & $217^{\star *}$ & 49.10 \\
\hline
\end{tabular}

Denotes a statistically significant difference between NPS users and non-NPS users, ${ }^{*} P<0.05$ and ${ }^{* *} P<0.001$.

CTO, compulsory treatment order; EDC, Emergency Detention Certificate; F00-F09, Organic, including symptomatic, mental disorders; F10-19, Mental and behavioural disorders due to psychoactive substance use; F20-F29, Schizophrenia, schizotypal and delusional disorders; F30-39 Mood (affective) disorders; F40-F49, Anxiety, dissociative, stress-related, somatoform and other non-psychotic mental disorders; F50-F59, Behavioural syndromes associated with physiological disturbances and physical factors; F60-F69, Disorders of adult personality and behaviour; F70-F79, Mental retardation; F80-89, Disorders of psychological development; ICD, International Statistical Classification of Diseases and Related Health Problems; MDMA, 3,4-methylenedioxymethamphetamine; MHA, Mental Health Act; NPS, novel psychoactive substances; Other, $\mathrm{b}$ and emotional disorders with onset usually occurring in childhood and adolescence/unspecified mental disorder; STDC, Short-Term Detention Certificate.

$95 \%$ CI 1.29 to $6.37, \mathrm{P}=0.007)$. NPS users were more likely to be men (OR 2.92, CI 1.28 to $6.66, \mathrm{P}=0.009$ ) and have a forensic history recorded in their discharge letter (OR 5.03, CI 2.39 to 10.59, $\mathrm{P}<0.001$ ) compared with non-NPS users. However, no statistical differences between NPS users and non-NPS users were observed in the proportions of patients recorded to have served custodial sentences.

NPS users were significantly more likely to use illicit substances other than NPS compared with non-NPS users (OR 5.44, 95\% CI 2.05 to $14.43, \mathrm{P}<0.001$ ). Compared with non-NPS users, NPS users were significantly more likely to use cannabis (OR 4.56, CI 2.17 to $9.58, \mathrm{P}<0.001$ ), non-substitute opiates (OR 2.85, CI 1.16 to $7.03, \mathrm{P}=0.018$ ), 3,4-methylenedioxymethamphetamine (MDMA) (OR 3.94, CI 1.23 to $12.61, \mathrm{P}=0.013$ ) and other uncategorised substances, which included hallucinogens and illegally acquired prescription drugs (OR 5.88, CI 1.97 to 17.58 , $\mathrm{P}<0.001)$.

Figure 3 reveals that ICD-10 diagnosis groupings for NPS users compared with non-NPS users were more likely to be F10-19 (OR 9.97, 95\% CI 4.62 to $21.49, \mathrm{P}<0.001$ ) and less likely to be F30-39 (OR 0.07, CI 0.009 to 0.516 , $\mathrm{P}<0.001)$. The most significant difference in diagnosis was for mental and behavioural disorders due to multiple drug use and use of other psychoactive substances disorder (ICD-10 F19), (OR 28.66, CI 11.85 to 69.30, P<0.001).

NPS users compared with non-NPS users were found to be significantly more likely to present with paranoia (OR $2.34,95 \%$ CI 1.08 to $5.08, \mathrm{P}=0.036)$ and thought disorder (3.44, CI 1.50 to $7.90, \mathrm{P}=0.002)$ and less likely to present with low mood (OR 0.29 , CI 0.11 to $0.76, \mathrm{P}=0.007$ ) and suicidal thoughts (OR 0.129, CI 0.03 to $0.550, \mathrm{P}=0.001$ ).

\section{DISCUSSION}

\section{Principal findings}

The present study builds on the findings made by Stanley et $a t^{25}$ by evaluating the impact of recent public health changes. As well as acute psychiatric inpatients, a second cohort was included, which comprised patients admitted to IHTT-a

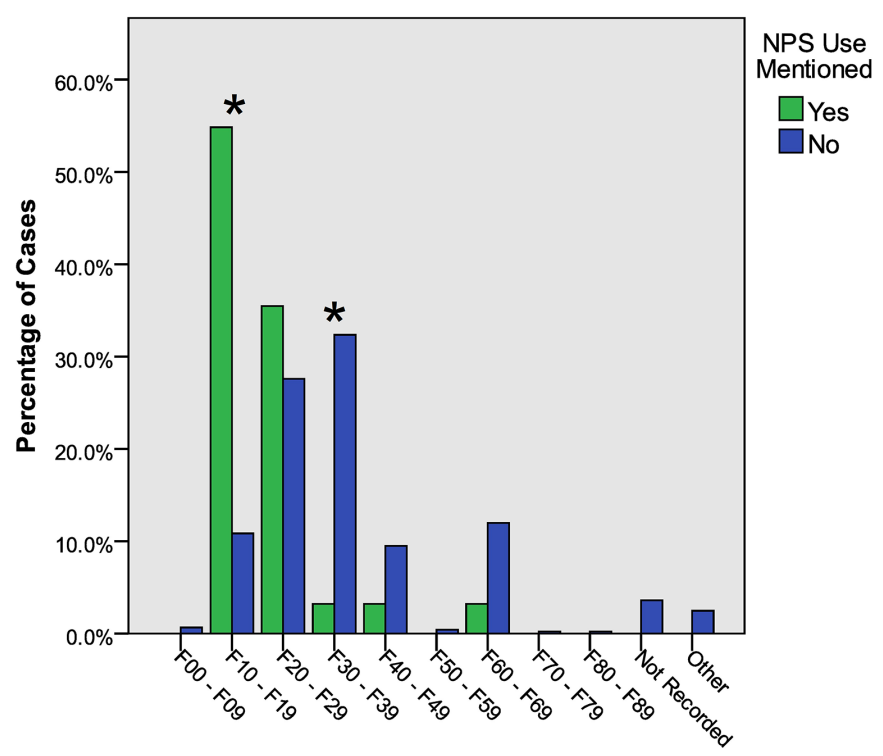

Principal Diagnosis ICD-10 Group

Figure 3 The percentage of NPS users and non-NPS users assigned principal diagnoses in accordance with ICD10 groups. *Denotes a statistically significant difference between NPS users and non-NPS users $\left(\chi^{2}\right), P<0.001$. ICD, International Statistical Classification of Diseases and Related Health Problems, Version 10; NPS, novel psychoactive substances. 
population previously not considered. We hypothesised that since public health interventions, the prevalence of NPS use in psychiatric patients has fallen. In contrast to the prevalence of $22.2 \%$ found by the previous work in psychiatric inpatients, ${ }^{25}$ the present data revealed a prevalence of NPS use in this group of $6.6 \%$ following recent public health interventions-a $15.6 \%$ reduction. Additionally, the prevalence of NPS use reported in discharge letters from the IHTT cohort was found to be $3.4 \%$. The present study found that of the NPS types recorded, a considerable proportion $(24.2 \%)$ were stimulants, several of which are reported to include more than one active ingredient. The relative popularity of this diverse group of chemicals may suggest that other compounds have been recently adopted by NPS users as a substitute for ethylphenidate since the TCDO.

\section{Strengths and weaknesses}

Unfortunately, a large proportion of demographic outcome measures $(54.84 \%$ employment and $35.48 \%$ home circumstances) were not recorded in discharge letters and due to the relatively small sample size, it is not possible to comment on these. Generally, demographic characteristics were similar to those found in the previous study ${ }^{25}$ : NPS users were more likely to be men, polysubstance misuse was more likely and mean age was similar (35.1 compared with 36.1 years old). The age distribution of NPS users was studied more thoroughly, however, and a bimodal distribution was observed with peaks in the 18-25 and 41-45 age groups, the latter of which was significant compared with non-NPS users. This is broadly in agreement with the findings of the DrugWise NPS: Come of Age report, ${ }^{35}$ which suggested that NPS use is not confined to a single generation; NPS perhaps appeal to the 18-25 age group as have 'club drugs' like mephedrone ${ }^{4}$ and 'party pills', such as those containing piperazine compounds. ${ }^{36}$ Conversely, the $41-45$ age group may use NPS as drug substitutes-so-called substance displacement, a phenomenon that has previously reported for synthetic cannabinoids. ${ }^{37}$ As in the previous work, ${ }^{25}$ the present study suggested that NPS users were more likely to use cannabis concomitantly; however, rather than a higher prevalence of substitute opiates it was found that NPS users within this study were more likely to use non-substitute opiates and MDMA. It is possible that these drug choices relate again to the prominent age groups observed-MDMA users aged 18-25 years have previously been shown to be more likely to use NPS, particularly synthetic cannabinoids, phenethylamines and synthetic cathinones ${ }^{38}$; and ethylphenidate has been implicated in opiates users, which may correspond to the 41-45 age group. ${ }^{16}{ }^{17}$ To assess differences in diagnoses between NPS users and non-NPS users, this study adopted a standardised approach by recording ICD-10 codes. The most common principal diagnosis assigned to NPS users was F19.5 (mental and behavioural disorders due to multiple drug use and use of other psychoactive substances: psychotic disorder). Previous work also found that this was the most commonly recorded diagnosis. ${ }^{25}$ On the basis of the present data, it is not possible to demonstrate a causal link between NPS and drug-induced psychosis. However, evidence from this study suggests that public health interventions may be effective in reducing the prevalence of NPS use in individuals vulnerable to their effects on mental state. In an effort to quantify the strain of these admissions on psychiatric services, length of stay and use of the $\mathrm{MHA}^{29}$ were examined. Compared with Stanley $e t a l,{ }^{25}$ it was found that almost double the proportion of NPS users in this study were detained and significant differences were observed in the use of EDC between NPS users and non-NPS users. Initially this could, in combination with the above findings regarding diagnosis, suggest that more users than in the earlier study are presenting severely psychotic enough to warrant detention. However, this finding should be interpreted with caution as changes in the working patterns of medical staff locally has consequently resulted in more out-of-hours detentions placed by junior medical staff, who are only able to detain under an EDC. This change in practice may be acting as a confounding factor for an apparent increase in this type of detention for patients. Psychotic episodes in patients using synthetic cannabinoids have been documented previously as transient and acute ${ }^{39}$; no significant differences in average length of stay between NPS users and non-NPS users were found. The total length of stay in this group accounts for $4 \%$ of length of stay across all patients, which is a smaller proportion than the proportion of NPS users within the general psychiatry cohort $(6.6 \%)$. Thus, no disproportionate or considerable strain on services has been observed at present and due to lack of data from Stanley $e t a l,{ }^{25}$ it is not possible to evaluate if there has been any significant change.

\section{Limitations and future research}

The study period covered 1 October 2015 to 31 March 2016, a 6-month period encompassing significant public health changes with regard to NPS. It is unfortunately not possible to say which of the two public health changes is associated with the reduction in prevalence of NPS use. However, these interventions together represent a ban and a seizure of supplies, and conclusions can be drawn about the collective impact of these changes. While comparisons may be made with the previous study, it is important to bear in mind that Stanley et $a l^{25}$ examined admissions during the months of July and August and it is possible that seasonal differences may have some influence here. ${ }^{40}$ One limitation is that the sample size of patients admitted to hospital/IHTT following NPS use is small and it most likely represents a small minority of the whole NPS using population. Recent data have estimated that 937000 people aged 16-59 in England and Wales had used an NPS at least once and 279000 in the past year. ${ }^{41}$ With limited data on the prevalence and demographics of NPS use in the general population, it is only possible to apply conclusions drawn in this study to psychiatric inpatients. Due to the nature of the study design, it is also possible that NPS use prevalence was underestimated. Furthermore, reviewing discharge letters is vulnerable to two forms of bias: reporting bias, in which the quality of discharge letters is heterogeneous, and observer bias, 
which arises due to variation in summarising recorded clinical impressions. The study aimed to reduce observer bias by reporting only explicitly positive NPS use cases and coding all others as non-NPS cases. This relies on clinicians directly inquiring into NPS use. Some discharge letters stated that NPS use was unknown but clinically suspected, which is perhaps a consequence of clinicians not routinely asking about NPS use when interviewing patients. In cases where NPS users were identified by clinical inquiry, inadequate recording of NPS types across both cohorts highlights poor recognition of the contribution NPS may have to psychiatric illness, perhaps due to a lack of relevant training for healthcare practitioners. ${ }^{42}$ The NEPTUNE project, a clinical guidance project, has made significant progress in resolving this gap by constructing an extensive document detailing the presentation and management of numerous NPS. ${ }^{43}$ Assuming inquiry by clinicians, the recording of NPS use is still limited as this approach relies on self-reporting by patients. It is also possible that patients using other substances are unintentionally also ingesting NPS as has been reported in a population aged 18-25 years of club-goers who tested positive for a range of empathogen NPS despite denying any NPS use. ${ }^{44}$ Ideally, laboratory analysis would have provided empirical evidence of NPS use and allowed for determination of the active ingredients ingested. Clinical screening for NPS is not routinely employed in clinical practice and limitations in immunoassays, particularly the variable cross-reactivity for different NPS lowers their sensitivity. ${ }^{45}$ However, chromatographic methods offer an alternative approach; liquid chromatography-tandem mass spectrometry of the urine has shown promise in identifying a diverse range of NPS and has been successfully implemented in a clinical setting. ${ }^{46}$ Use of such biochemical techniques would allow for reliable measurements in future studies relating to NPS use. While there are limitations associated with a retrospective review, it is useful for providing epidemiological findings and, as such, was deemed appropriate here for relatively simple data collection from an electronic patient database. Furthermore, this design provides a quantitative report on NPS users in contrast to the relative abundance of case reports in the literature, which do not allow for reliable systematic reviews to be conducted. ${ }^{47}$ In order to address the methodological issue of poor recording of NPS use by clinicians, a long-term prospective cohort study could be carried out using standardised pro formas with well-defined reporting criteria available on wards. This type of study would be of particular benefit across the UK in the period following the Psychoactive Substances Act (2016) ${ }^{22}$ More detailed analysis of NPS users will also identify whether these patients are previously known to suffer a psychiatric illness, what services they subsequently use and if these patients successively develop chronic psychiatric illnesses.

\section{Generalisability}

Since the TCDO placed on ethylphenidate and forfeiture orders of NPS within Edinburgh, there has been a reduction in the prevalence of NPS use in psychiatric admissions locally. This study does not aim to suggest there is a causal link between NPS and psychiatric illness, but other studies have provided evidence to support this link. ${ }^{15}$ The current findings instead suggest that prohibitive legislation coupled with the intensive and organised seizure of NPS may have contributed to the reduction of NPS-related admissions to acute psychiatric wards and to a local crisis team. The advent of the Psychoactive Substances Act $(2016)^{22}$ criminalises the supply of NPS, and thus provides an opportunity to assess similar policy changes implemented on a national level. In response to the rise of NPS, New Zealand has adopted a regulatory licensing system whereby NPS can be approved for use if it is felt that there is a low risk of associated harm. ${ }^{48}$ Elsewhere, however, countries have taken 'blanket ban' stances similar to the Psychoactive Substances Act (2016), ${ }^{22}$ and these have failed to demonstrate reductions in NPS use and availability. ${ }^{49}$ The present findings suggest that selective prohibition and general confiscation may be effective in reducing NPS-related admissions. While these findings are from a population requiring psychiatric admission 6 months after public health measures were implemented, such results may be sustained and common to other clinical specialties. Future studies could be carried out to examine the impact of the Psychoactive Substances Act $(2016)^{22}$ on psychiatric and general hospital admissions.

Acknowledgements The authors acknowledge Dr Rebecca J Lawrence and Dr Daniel V Mogford for their advice on format of this study, which is based on their previous work.

Contributors The study design was adapted from the work of Stanley et al (2016), and the protocol was written by HLA. KHB collected and analysed the data. RMW supported the data collection process. $\mathrm{HMH}$ collected a sample of data as a means of quality control. HLA provided supervision on aspects of data collection. SL supervised all aspects of the project. All authors contributed to the review and editing of the final manuscript.

Funding This work was supported by the University of Edinburgh School of Medicine, which provided a basic salary for the primary author of this study.

Competing interests None declared.

Ethics approval Quality Improvement Team at Royal Edinburgh Hospital.

Provenance and peer review Not commissioned; externally peer reviewed.

Data sharing statement Extra data can be accessed via the Dryad data repository at http://datadryad.org/ with the doi:10.5061/dryad.db1h7.

Open Access This is an Open Access article distributed in accordance with the Creative Commons Attribution Non Commercial (CC BY-NC 4.0) license, which permits others to distribute, remix, adapt, build upon this work non-commercially, and license their derivative works on different terms, provided the original work is properly cited and the use is non-commercial. See: http://creativecommons.org/ licenses/by-nc/4.0/

(c) Article author(s) (or their employer(s) unless otherwise stated in the text of the article) 2017. All rights reserved. No commercial use is permitted unless otherwise expressly granted.

\section{REFERENCES}

1. European Monitoring Centre for Drugs and Drug Addiction. Action on new drugs, 2016. http://www.emcdda.europa.eu/activities/action-onnew-drugs (accessed 4 Dec 2016). 
2. Liechti M. Novel psychoactive substances (designer drugs): overview and pharmacology of modulators of monoamine signaling. Swiss Med Wkly 2015;145:w14043.

3. European Monitoring Centre for Drugs and Drug Addiction. New psychoactive substances inEurope. An update from the EU Early Warning System, 2015. http://www.emcdda.europa.eu/system/files/ publications/65/TD0415135ENN.pdf (accessed 4 Dec 2016).

4. Moore K, Dargan PI, Wood DM, et al. Do novel psychoactive substances displace established club drugs, supplement them or act as drugs of initiation? The relationship between mephedrone, ecstasy and cocaine. Eur Addict Res 2013;19:276-82.

5. Corazza O, Valeriani G, Bersani FS, et al. "Spice," "kryptonite," "black mamba": an overview of brand names and marketing strategies of novel psychoactive substances on the web. J Psychoactive Drugs 2014;46:287-94.

6. McAuley A, Hecht G, Barnsdale L, et al. Mortality related to nove psychoactive substances in Scotland, 2012: an exploratory study. Int J Drug Policy 2015;26:461-7.

7. European Monitoring Centre for Drugs and Drug Addiction. New psychoactive substances - Understanding the market for new psychoactivesubstances in Europe. EU drug markets report, 2016. http://www.emcdda.europa.eu/publications/eu-drug-markets/2016/ online/new-psychoactive-substances/market (accessed 4 Dec 2016).

8. Advisory Council on the Misuse of Drugs. Methylphenidate-based NPS: a review of the evidence of use and harm, 2015. https://www. gov.uk/government/uploads/system/uploads/attachment data/file/ 420983/TCDO_methylphenidate_NPS.pdf (accessed 4 Dec 2016).

9. Lafferty C, Smith L, Coull A, et al. The experience of an increase in the injection of ethylphenidate in Lothian April 2014-March 2015. Scott Med J 2016;61:74-83.

10. Home Office. Annual report on the home office forensic early warning system (FEWS) a system to identify new psychoactive substances in the UK. 2012 https://www.gov.uk/government/uploads/system/ uploads/attachment data/file/225840/fews.pdf (accessed 4 Dec 2016).

11. Bluelight.org. Bluelight - forum - focus forums, other drugs Ethylphenidate. 2010 http://www.bluelight.org/vb/threads/499397Ethylphenidate (accessed 4 Dec 2016).

12. Ho JH, Bailey GP, Archer JR, et al. Ethylphenidate: availability, patterns of use, and acute effects of this novel psychoactive substance. Eur J Clin Pharmacol 2015;71:1185-96.

13. Bailey GP, Ho JH, Hudson S, et al. Nopaine no gain: recreational ethylphenidate toxicity. Clin Toxicol 2015;53:498-9.

14. Soussan C, Kjellgren A. "Chasing the high" - experiences of ethylphenidate as described on international internet forums. Subst Abuse 2015;9:SART.S22495.

15. Schifano F, Orsolini L, Duccio Papanti G, et al. Novel psychoactive substances of interest for psychiatry. World Psychiatry 2015;14:15-26.

16. Parks $C$, McKeown D, Torrance HJ. A review of ethylphenidate in deaths in east and west Scotland. Forensic Sci Int 2015;257:203-8.

17. Maskell PD, Smith PR, Cole R, et al. Seven fatalities associated with ethylphenidate. Forensic Sci Int 2016;265:70-4.

18. United Kingdom Parliament. The Misuse of drugs act 1971 (Temporary Class Drug) Order2015. S.I. 2015/1027, 2015.

19. Home Office. Circular 015/2015: temporary control of 5 methylphenidate-based NPS. 2015 https://www.gov.uk/ government/publications/circular-0152015-temporary-control-of-5methylphenidate-based-nps/circular-0152015-temporary-control-of5-methylphenidate-based-nps (accessed 4 Dec 2016).

20. Iverson L. Advisory Council on the Misuse of Drugs. Re: TCDOs and ACMD position on methylphenidate-based NPS. $2016 \mathrm{https}: / / \mathrm{www}$. gov.uk/government/uploads/system/uploads/attachment data/file/ 503873/TCDO_Letter_-_phenidates_and_12_month_29_Feb_2016. pdf (accessed 4 Dec 2016).

21. Bury J. The City of Edinburgh Council Health, Social Care and Housing Committee. Novel psychoactive substances - trading standards enforcement action. 2015 www.edinburgh.gov.uk/downloa d/meetings/id/48793/item710novelpsychoactive_subsdtancestradi ng_standards_enforcementaction (accessed 4 Dec 2016).

22. United Kingdom Parliament. Psychoactive Substances Act, 2016.

23. Wood DM, Hunter L, Measham F, et al. Limited use of novel psychoactive substances in South London nightclubs. QJM 2012;105:959-64.

24. Brandt SD, Sumnall HR, Measham F, et al. Analyses of secondgeneration 'legal highs' in the UK: initial findings. Drug Test Anal 2010;2:377-82.
25. Stanley JL, Mogford DV, Lawrence RJ, et al. Use of novel psychoactive substances by inpatients on general adult psychiatric wards. BMJ Open 2016;6:e009430.

26. InterSystems. TrakCare - Unified healthcare information system, 2016. http://www.intersystems.com/our-products/trakcare/trakcareoverview-2/ (accessed 4 Dec 2016).

27. SAP. SAP BusinessObjects Business Intelligence, 2016. http://go. sap.com/uk/product/analytics/bi-platform.html (accessed 4 Dec 2016).

28. World Health Organization. International statistical classification of diseases and related health problems: World Health Organization, 2004.

29. Scottish Parliament. Mental Health (Care and Treatment) (Scotland) Act 2003. a.s.p. 13, 2003.

30. Scottish Care Information - Information Services of the NHS National Services Scotland. SCI Store, 2015. http://www.sci.scot.nhs.uk/ products/store/store_main.htm (accessed 21 Dec 2016).

31. Crew 2000. Crew - Drugs Index. 2016. http://m.crewknowledge. com/ListAllDrugs.php (accessed 4 Dec. 2016).

32. Adley M. Drug Watch. The drugs wheel - a new model for substance awareness. 2017 http://www.thedrugswheel.com/downloads/ TheDrugsWheel_2_0_4.pdf (accessed 26 May 2017)

33. Helander A, Beck O, Bäckberg M. Intoxications by the dissociative new psychoactive substances diphenidine and methoxphenidine. Clin Toxicol 2015;53:446-53.

34. Chemical Lab. K-PAX | Chemical Lab. 2015 http://chemicallab.co.uk/ product/k-pax/ (accessed 26 May 2017).

35. Shapiro H D. NPS come of age: A UK overview.2016 http://www. drugwise.org.uk/wp-content/uploads/NPSComeofAge.pdf (accessed 4 Dec 2016)

36. Zamengo L, Frison G, Bettin C, et al. Understanding the risks associated with the use of new psychoactive substances (NPS): high variability of active ingredients concentration, mislabelled preparations, multiple psychoactive substances in single products. Toxicol Lett 2014;229:220-8.

37. Kjellgren A, Andersson M. Aspects of substance displacement-from Illicit drugs to novel psychoactive substances. J Addict Res Ther 2016.

38. Palamar JJ, Acosta P, Sherman S, et al. Self-reported use of novel psychoactive substances among attendees of electronic dance music venues. Am J Drug Alcohol Abuse 2016;42:624-32.

39. Papanti D, Schifano F, Botteon G, et al. "Spiceophrenia": a systematic overview of "spice"-related psychopathological issues and a case report. Hum Psychopharmacol 2013;28:379-89.

40. Home Office. News story - Festivals warned over drug use, 2011 https://www.gov.uk/government/news/festivals-warned-over-druguse (accessed 4 Dec 2016)

41. Lader D. Home Office. Drug misuse: findings from the 2014/15 crime survey for england and wales. $2015 \mathrm{https} / / / \mathrm{www}$. gov.uk/government/ uploads/system/uploads/attachment_data/file/462885/drug-misuse1415.pdf (accessed 4 Dec 2016).

42. Public Health England. New psychoactive substances: toolkit for commissioners, 2014. http://www.nta.nhs.uk/uploads/nps-a-toolkitfor-substance-misuse-commissioners.pdf. (accessed 4 Dec. 2016).

43. Novel Psychoactive Treatment UK Network - NEPTUNE. Guidance on the clinical management of acute and chronic harm of club drugs and novel psychoactive substances. $2015 \mathrm{http}: / /$ neptune-clinicalguidance.co.uk/wp-content/uploads/2015/03/NEPTUNE-GuidanceMarch-2015.pdf (accessed 4 Dec 2016).

44. Palamar JJ, Salomone A, Vincenti M, et al. Detection of "bath salts" and other novel psychoactive substances in hair samples of ecstasy/ MDMA/"Molly" users. Drug Alcohol Depend 2016;161:200-5.

45. Favretto D, Pascali JP, Tagliaro F. New challenges and innovation in forensic toxicology: focus on the "New Psychoactive Substances". J Chromatogr A 2013;1287:84-95.

46. Al-Saffar Y, Stephanson NN, Beck O. Multicomponent LC-MS/MS screening method for detection of new psychoactive drugs, legal highs, in urine-experience from the Swedish population. $J$ Chromatogr B Analyt Technol Biomed Life Sci 2013;930:112-20.

47. Gray R, Bressington D, Hughes $E$, et al. A systematic review of the effects of novel psychoactive substances 'legal highs' on people with severe mental illness. J Psychiatr Ment Health Nurs 2016;23:267-81.

48. Parliament NZ. Psychoactive Substances Act 2013. Public Act 2013;53:17.

49. Stevens A, Fortson R, Measham F, et al. Legally flawed, scientifically problematic, potentially harmful: The UK Psychoactive Substance Bill. Int J Drug Policy 2015;26:1167-70. 